\title{
OS LIMITES DO DISCURSO DO DESENVOLVIMENTO ECONÔMICO E OS DIREITOS FUNDAMENTAIS: O CASO DA LIBERDADE NA PÓS- MODERNIDADE
}

\section{THE LIMITS OF THE ECONOMIC DEVELOPMENT AND FUNDAMENTAL RIGHTS SPEECH: THE CASE OF FREEDOM IN POSTMODERNITY}

\author{
Naína Ariana Souza Tumelero \\ Estudante de direito pela Universidade Comunitária Regional de Chapecó (UNOCHAPECÓ). Chapecó, Santa Catarina, \\ Brasil. \\ naina@unochapeco.edu.br \\ GiOVANNI OLSSON \\ Doutor em Direito pela Universidade Federal de Santa Catarina (UFSC). Professor vinculado ao Programa de Pós- \\ Graduação em Direito da UNOCHAPECÓ. Chapecó, Santa Catarina, Brasil. \\ golsson71@gmail.com
}

\begin{abstract}
RESUMO
O artigo estuda a relação entre desenvolvimento econômico e direitos fundamentais, especialmente a liberdade na pós-modernidade. 0 trabalho pesquisa 0 desenvolvimento econômico por óticas contrapostas e a evolução conceitual de direito fundamental como categoria. Investiga também sua conexão com o Direito Fundamental da Liberdade na pósmodernidade. Demonstra que os processos de transformações ocorridas nos pilares que fundaram a modernidade, e sua posterior crise, com o passar dos anos, influenciaram as dinâmicas sociais, atingindo, por consequência, os campos das liberdades individuais e do desenvolvimento econômico. As modificações no conceito dos direitos fundamentais ao longo deste processo alteraram a compreensão da própria categoria, e, embora o termo desenvolvimento seja usualmente utilizado de forma descuidada, este constitui um conceito controverso e complexo. 0 estudo aponta que a liberdade, enquanto direito humano e fundamental, é significativamente impactada pelo desenvolvimento econômico.
\end{abstract}

Palavras-chave: Desenvolvimento; direitos fundamentais; liberdade; pós-modernidade.

\begin{abstract}
The article studies the relation between economic development and fundamental rights, especially in what it regards to liberty in postmodernity. The work researches economic development discourse on opposite trends and evolution of the concept of fundamental right as a category. Moreover, it investigates its connections with citizen rights and human rights in the realm of the fundamental right of freedom in postmodernity. It demonstrates that the transformative processes in groundings of modernity, the crisis that followed, and postmodernity, challenged social dynamics over time, hitting, consequently, the fields of individual freedom and economic development. Therefore, transformations in the concept of fundamental rights along this process changed the category's comprehension of itself, and although development is a word usually adopted recklessly, it is a very controversial and complex concept. The article finally states that liberty, as a human and fundamental right, is highly impacted by economic development.
\end{abstract}

Keywords: Development; fundamental rights; freedom; postmodernity. 


\section{SUMÁRIO}

INTRODUÇÃO; 1 A ASCENSÃO DO DISCURSO DOS DIREITOS FUNDAMENTAIS; 2 A PÓS-MODERNIDADE; 2.1 A formação e a crise da Modernidade; 2.2 A emergência da Pós-modernidade; 3 O DESENVOLVIMENTO ECONÔMICO NA PÓS-MODERNIDADE; CONCLUSÃO; REFERÊNCIAS.

\section{INTRODUÇÃO}

0 presente artigo tem como objetivo estudar a relação entre o Desenvolvimento Econômico e os Direitos Fundamentais, especialmente no tocante à Liberdade na Pósmodernidade.

No primeiro momento, deve-se analisar a ascensão do discurso dos Direitos Fundamentais, por meio da contextualização terminológica de Direitos Naturais, Humanos e Fundamentais, que, embora devidamente conceituados, atendem homogeneamente pelo termo "Direitos Fundamentais", pela abrangência, a fim de atingir o objetivo buscado no trabalho. A escolha do Direito Humano específico da liberdade justifica-se pela sua relevância e extenso espectro, apesar de sua aparente falta de definição clara.

No segundo momento, cabe a exposição do surgimento do Projeto Filosófico da Modernidade, com uma breve contextualização acerca de seus princípios fundamentais, e sua posterior crise, resultando na Pós-modernidade tratada no texto.

No terceiro momento, deve ser estudado o desenvolvimento econômico como uma categoria conceitual que serve de referência para a análise da sociedade e de suas riquezas, inclusive a relação daquele com a globalização econômica. Por fim, o estudo procura identificar de que forma esse referencial está conectado com a questão dos direitos fundamentais, especialmente o da liberdade, na pós-modernidade.

\section{A ASCENSÃO DO DISCURSO DOS DIREITOS FUNDAMENTAIS}

O debate sobre os direitos fundamentais é uma temática nunca esgotada, porque, ainda que muito estudada, mantém-se atual por estar em constante modificação e renovação, especialmente ao acompanhar as próprias transformações da sociedade. Tais direitos 
acompanharam, acompanham e continuarão acompanhando as transformações dos fatos e valores do meio social, e, por isso, tendem a retratar suas necessidades e inquietações.

Há de se ressaltar a existência de extensas discussões terminológicas referentes à utilização das expressões “Direitos Fundamentais", “Direitos do Homem” e "Direitos Humanos”. Muito embora, num primeiro momento, a terminologia utilizada pareça não comprometer o sentido que se busca, quando da análise dos documentos referentes ao tema esta distinção fazse necessária.

Neste processo, no tocante à acepção conceitual, tem-se que os direitos do homem emergiram como direitos naturais universais, tornando-se, em seu desenvolvimento, direitos positivos particulares e, somente ao fim, encontram sua plena realização como direitos positivos universais ${ }^{1}$.

Acerca de tal desenvolvimento, e concernente à sua trajetória, Bobbio ${ }^{2}$ ainda distingue as fases do processo. A primeira delas é tida como a afirmação dos direitos de liberdade, que envolvem todos aqueles direitos que tendem a limitar o poder do Leviatã e a reservar para o indivíduo, ou para os grupos particulares, uma esfera de liberdade em relação ao Estado. A segunda deu-se na consolidação dos direitos políticos, que proporcionaram a participação cada vez mais ampla, generalizada e intensa dos membros de uma comunidade no poder político, o que se pode traduzir em liberdade no Estado. 0 diferencial que caracteriza tais direitos está na sua concepção, que se dá não apenas de forma negativa, como um "não-impedimento", mas positivamente, como autonomia e afirmação.

A desnecessidade de justificação e de conceituação subjetiva dos Direitos Humanos é explicada por Alexy ${ }^{3}$, ao constatar que, aparentemente, a falta de um questionamento correto e preciso explicaria a falta de consenso referente à terminologia, isto porque, sem clareza, não se sabe qual questionamento o conceito deveria responder. A problemática do fundamento destes direitos, para Bobbio ${ }^{4}$, por sua vez, reside na diferença entre se buscar "um direito que se tem" e um "direito que se gostaria de ter".

\footnotetext{
${ }^{1}$ BOBBIO, Norberto. A era dos direitos. Tradução de Carlos Nelson Coutinho. Rio de Janeiro: Campus, 1992, p. 31.

2 Ibidem, p. 32-33.

${ }^{3}$ ALEXY, Robert. Teoría de los derechos fundamentales. 2. ed. Madrid. Centro de Estudios Politicos y Constitucionales, 2008, p. 151.

${ }^{4}$ BOBBIO, Norberto. A era dos direitos. Tradução de Carlos Nelson Coutinho. Rio de Janeiro: Campus, 1992, p. 15.
} 
Neste contexto, é importante a análise de $A_{\text {lexy }}^{5}$, ao correlacionar os Direitos Fundamentais às normas e aos princípios. Para o autor, a existência de um direito fundamental cria uma norma válida de direito, mas o contrário parece não acontecer, ou seja, se existissem normas de direito fundamental que não outorgassem nenhum direito subjetivo, elas não teriam validade.

Sendo a existência de um direito subjetivo diretamente conectado com a previsão normativa, a afirmação dessa categoria jurídica deixa de ser apenas filosófica ou hipotética, e passa a ser, essencialmente, jurídico-normativa. Assim, mesmo que os direitos do homem sejam fundamentais, eles são também históricos, oriundos gradualmente de lutas em defesa de novas liberdades contra velhos poderes, "nem todos de uma vez e nem de uma vez por todas" 6 . Por isso, concorda Sarlet ${ }^{7}$, ao explicar que os direitos fundamentais serão sempre humanos, uma vez que o ser humano é, e sempre será, o titular dele.

A respeito da importância das concepções históricas da doutrina dos direitos naturais, Bobbio $^{8}$ alerta que os Direitos do Homem como Direitos Fundamentais não são assim pela simples "natureza", mas sim por uma contingência histórica, porque em certa época e em determinada civilização um direito pode ser visto como fundamental, mas, em outro momento ou outra cultura, não. Essas constantes variações conceituais de tais direitos fazem com que, conforme ainda preleciona Bobbio ${ }^{9}$, não haja razão para a busca de um fundamento absoluto dos direitos do homem.

Mesmo que, corriqueiramente, os termos "direitos humanos" e "direitos fundamentais" sejam utilizados como sinônimos, Sarlet ${ }^{10}$ faz relevante distinção quando justifica a aplicação do segundo para aqueles direitos do ser humano que já estão reconhecidos e positivados constitucionalmente em determinado Estado.

\footnotetext{
${ }^{5}$ ALEXY, Robert. Teoría de los derechos fundamentales. 2. ed. Madrid. Centro de Estudios Politicos y Constitucionales, 2008, p. 31.

${ }^{6}$ BOBBIO, Norberto. A era dos direitos. Tradução de Carlos Nelson Coutinho. Rio de Janeiro: Campus, 1992, p. 5.

${ }^{7}$ SARLET, Ingo Wolfgang. A eficácia dos direitos fundamentais. Porto Alegre: Livraria do Advogado, 1998, p. 31.

8 Ibidem, p. 19.

9 BOBBIO, Norberto. A era dos direitos. Tradução de Carlos Nelson Coutinho. Rio de Janeiro: Campus, 1992, p. 22.

${ }^{10}$ Ibidem.
} 
Nesse sentido, a liberdade, para Alexy ${ }^{11}$, constitui um dos mais fundamentais e, paradoxalmente, menos claros direitos, tendo este um extenso âmbito de aplicação. Bobbio ${ }^{12}$, na mesma linha, resgata a lição kantiana, ao recordar que todos os direitos “irresistíveis" ou “inatos” são, em verdade, sintetizados em apenas um: a liberdade.

Alexy ${ }^{13}$ pondera que a grande dificuldade de conceituação da liberdade é aumentada quando interpretada por uma visão emotiva, uma vez que abre a possibilidade de uma definição persuasiva, como, por exemplo, no desejo de impulsionar alguém a realizar algo. Na sua leitura, esse pode ser um dos fatos que mantenha a polêmica sobre o conceito de liberdade, no sentido de que, quando do desejo de impulsionar alguém para executar determinada ação, pode-se utilizar a liberdade como argumento, como se a liberdade em si mesma consistisse nesta execução. Neste sentido, o conceito de liberdade jurídica pode ser explicado de duas maneiras: como uma manifestação especial de um conceito mais amplo de liberdade, ou como um conceito constitutivo próprio, ou seja, jurídico.

A primeira delas, em verdade, constitui a pergunta do que é a liberdade em si mesma, o que conduziria a um ambicioso projeto de desenvolvimento de uma filosofia da liberdade; a segunda, de outro lado, volta-se à estrutura do conceito de liberdade, que se torna menos ambicioso, tendo-se a perspectiva de uma resposta mais exitosa, e, provavelmente negativa. Nas palavras do autor, "[...] quem disse que uma pessoa é livre pressupõe que, para esta pessoa, não existem impedimentos, restrições ou resistências de algum tipo". Por isso, a liberdade nada mais seria do que a relação didática entre uma pessoa e um impedimento de liberdade ${ }^{14}$.

No concernente a essa relação entre um impedimento de liberdade e uma liberdade positivada, Bobbio ${ }^{15}$ esclarece que todas as recentes declarações dos direitos do homem compreendem mais do que direitos individuais tradicionais (que consistem em liberdades) ao exigir da parte dos outros (incluídos aqui os órgãos públicos) obrigações puramente negativas, que implicam a abstenção de determinados comportamentos. Os direitos sociais, que consistem em poderes, podem ser realizados apenas quando da imposição aos outros de certo número de

\footnotetext{
${ }^{11}$ ALEXY, Robert. Teoría de los derechos fundamentales. 2. ed. Madrid. Centro de Estudios Politicos y Constitucionales, 2008, p. 186.

12 BOBBIO, Norberto. A era dos direitos. Tradução de Carlos Nelson Coutinho. Rio de Janeiro: Campus, 1992, p. 17.

${ }^{13}$ ALEXY, Robert. Teoría de los derechos fundamentales. 2. ed. Madrid. Centro de Estudios Politicos y Constitucionales, 2008, p. 186-187.

${ }^{14}$ Ibidem, p. 187.

${ }^{15}$ BOBBIO, Norberto. A era dos direitos. Tradução de Carlos Nelson Coutinho. Rio de Janeiro: Campus, 1992, p. 21.
} 
obrigações positivas. Por isso, nas palavras de Bobbio ${ }^{16}$ : "quanto mais aumentam os poderes dos indivíduos, tanto mais diminuem as liberdades dos mesmos indivíduos".

Essa circunstância aparentemente paradoxal revela como se forma a soberania e a supremacia de uma nação, com a soma de todas essas porções de liberdades sacrificadas ao bem de cada um, sendo o Soberano o seu legítimo depositário e administrador, que, ao mesmo tempo em que restringe umas liberdades, também garante outras. Esta ótica de liberdade é ampliada na visão de Galtung ${ }^{17}$, que considera a análise das afirmações de "o que se faz aqui, quando, e com quem", tendo em vista que todas as sociedades conhecidas limitam essa liberdade de resposta, se não ao todo, pelo menos em parte, buscando regimentar e disciplinar a distribuição das atividades.

Com isso, nota-se profunda ligação entre a aplicação e a efetivação dos Direitos Fundamentais, em especial ao Direito da Liberdade, e o contexto social em cada momento histórico. Na sociedade contemporânea, por sua vez, o direito de liberdade deve ser compreendido diante da nova realidade de relações altamente complexas, dinâmicas e integradas em uma rede que se estende por todo o globo. Nesse particular, é essencial voltar o olhar agora para o peculiar contexto em que se vive: a pós-modernidade.

\section{A PÓS-MODERNIDADE}

\subsection{A formação e a crise da Modernidade}

0 projeto-filosófico da modernidade formou-se entre os séculos XVI e XVIII, tendo coincidido a sua afirmação histórica com a emergência do capitalismo como modo de produção dominante nos países da Europa que integraram a primeira grande onda de industrialização ${ }^{18}$. Embora sua construção decorra da convergência de inúmeros aportes teóricos, o projeto filosófico da modernidade está sustentado por três princípios fundamentais: o do Estado, articulado por Hobbes; do mercado, em que domina a obra de Locke; e o da comunidade, tendo a formulação centrada na filosofia política de Rousseau. Assim, e de início, faz-se necessário

\footnotetext{
${ }^{16}$ Ibidem, p. 21.

${ }^{17}$ GALTUNG, Johan. Direitos Humanos: uma nova perspectiva. Tradução de Margarida Fernandes. Lisboa: Instituto Piaget, 1994, p. 118.

${ }^{18}$ SANTOS, Boaventura de Sousa. Pela mão de Alice: o social e o político na pós-modernidade. 7 ed. São Paulo: Cortez, 2000, p. 78.
} 
incursionar, ainda que brevemente, nesses três pilares que embasam a modernidade e, logo a seguir, explicam a sua crise que projeta a pós-modernidade.

$\mathrm{Na}$ construção do primeiro destes princípios, o do Estado de Modelo Nacional, teve grande protagonismo a obra de Hobbes, que definiu a essência do Estado na ação de instituir, em uma pessoa, os atos de uma grande multidão. Isso ocorreria, segundo ele, por meio de pactos recíprocos, podendo o Estado inclusive usar a força e os meios de todos, da maneira que considerar conveniente, a fim de assegurar a paz e a defesa comum para todos ${ }^{19}$.

O segundo deles, o princípio da Comunidade, foi diretamente influenciado pelo "Contrato Social" de Rousseau. A base da comunidade, portanto, se fundaria em laços como os da família, que é a mais antiga e única sociedade natural. Neste exemplo, utilizado por Rousseau ${ }^{20}$, os filhos permanecem ligados ao pai somente enquanto têm necessidade dele para sua manutenção, e, cessando tal necessidade, esta ligação natural se dissolve, restando apenas a união de forma voluntária e fundamentada na sua vontade livre. Por isso, e na sua ótica, examinar o motivo de um povo ser um povo é mais relevante do que examinar o ato pelo qual um povo se torna um povo, e até mesmo de examinar o ato pelo qual um povo elege um rei. Afinal, para Rousseau ${ }^{21}$, o verdadeiro fundamento da sociedade é a formação do povo, e o seu "contrato" e a sua instauração do Estado são apenas consectários.

Além destes dois princípios, a transição para a Modernidade também veio acompanhada de uma profunda transformação no modo de produção econômico, associada a um terceiro princípio, o do Mercado. Neste, destaca-se a obra de Locke ${ }^{22}$, que baseou a economia no trabalho e na propriedade, e, em sua visão, ainda que a Terra e todas as demais criaturas inferiores pertençam a todos os homens, cada um deve garantir e assegurar a sua propriedade, sendo que ninguém além do proprietário exercerá direito sobre ela. Desta forma, a obra produzida pelo trabalho das mãos dos homens passa também a ser sua propriedade, no sentido que sempre que o homem tira um objeto colocado e deixado no Estado pela natureza e investe seu trabalho, acrescenta algo que o agrega, e, assim, isso também se torna sua propriedade.

\footnotetext{
${ }^{19}$ HOBBES, Thomas. Leviatã: ou matéria, forma e poder de um estado eclesiástico e civil. Tradução de Rosina D. Angina. 2 ed. São Paulo: Martin Claret, 2012, p. 140.

${ }^{20}$ ROUSSEAU, Jean-Jacques. Discurso sobre a economia política e do Contrato Social. Tradução de Maria Constança Peres Pissarra. Petrópolis: Vozes, 1996, p. 70.

${ }_{21}^{21}$ Ibidem, p. 78.

22 LOCKE, John. Segundo tratado sobre o governo civil: ensaio sobre a origem, os limites e os fins verdadeiros do governo civil. Tradução de Magda Lopes e Marisa Lobo da Costa. Petrópolis, RJ: Vozes, 1994, p. 198.
} 
Assentado em cima destes três pilares, nessa breve síntese, fundou-se a modernidade, que, para Coelho ${ }^{23}$, tem como mais marcante traço a prevalência do racionalismo como filosofia, opondo-se ao então prevalecente obscurantismo medieval. Claramente se visualiza a manifestação deste traço em diversos setores da sociedade, a exemplo da economia, por meio do capitalismo; da burocracia, como racionalização da administração; do positivismo, como racionalização da filosofia; e da dogmática, como forma de racionalizar o direito.

Outra característica notável é que, ideologicamente, a modernidade se concentrou no proprietarismo, a iniciar pela apropriação dominadora da natureza, o que provocou reações de caráter coletivista, como a negação da teoria da propriedade privada, o sentimento ecológico, o humanismo, e a crença no reinado do bem e da liberdade, mas esta ideologia provocou uma contrapartida de mal-estar, contestação, crise e falência ${ }^{24}$.

Juntamente com o racionalismo e o domínio da técnica, o apego ao materialismo, de caráter liberal ou coletivista, também constitui relevante característica da modernidade. Este conjuga-se à crença no progresso material, científico e social, a matematicidade, o geometrismo, o mecanicismo e a previsibilidade, favorecendo a tendência contrária ao "escapismo pseudo-espiritual", e resgatando os fantasmas da barbárie, do apocalipse, da anomia, da entropia e do $\operatorname{caos}^{25}$.

Neste sentido, especialmente no campo político, Coelho ${ }^{26}$ explica que a modernidade diferenciou-se do feudalismo como ciclo histórico ao centrar o poder político nas mãos de um soberano, se articulando, paralelamente, à unificação dos povos unidos pela ideia de nação com a institucionalização dos exércitos nacionais como forças militares permanentes. 0 Estado do período da modernidade, ou dito moderno, assim, é também um Estado de modelo nacional, que, ao incorporar a regulação jurídica na limitação e exercício do poder, passa a ser propriamente um Estado de Direito, ou, na célebre definição weberiana, o "modelo políticojurídico" da modernidade.

\subsection{A emergência da Pós-modernidade}

\footnotetext{
${ }^{23}$ COELHO, Luiz Fernando Coelho. Saudade do futuro. Curitiba: Juruá, 2007, p. 26.

${ }^{24}$ COELHO, Luiz Fernando. Saudade do futuro. Curitiba: Juruá, 2007, p. 24.

${ }^{25}$ Ibidem, p. 24.

${ }^{26}$ Ibidem, p. 25.
} 
A crise do projeto da modernidade, conforme antecipou Coelho ${ }^{27}$, apresentou-se a partir dos anos sessenta, quando diversos movimentos sociais posicionaram-se contra as imposições ideológicas dos setores mais conservadores da sociedade, para desmistificar a racionalidade, resgatar a liberdade criativa e a espontaneidade do homem, prevalecendo os fatores humanistas, como a intuição e o sentimento. Tal superação dos modelos epistêmicos, até então tradicionais, para Coelho ${ }^{28}$, é uma das consequências da crise da modernidade, afirmando um novo paradigma no atual horizonte das ciências sociais.

Por isso, o autor afirma que a principal característica da transição entre a modernidade e a pós-modernidade foi exatamente o espírito de revolta juvenil, apoiada pelos setores acadêmicos mais progressistas. No campo jurídico, a revolta se manifestou nas escolas zetéticas de interpretação jurídica, abrindo o caminho para o pensamento crítico manifestado no alternativismo jurídico-europeu ${ }^{29} \mathrm{e}$, depois, no próprio nascimento de direito alternativo latinoamericano, que, no ideal de Warat $^{30}$, estaria baseado em uma pluralidade de movimentos heterogêneos de tendências.

$\mathrm{Na}$ visão de Coelho ${ }^{31}$, ainda, até mesmo o simples uso da palavra modernidade ocasiona certas confusões e equívocos, visto que, mesmo em se tratando originalmente de um conceito historiográfico como referência de uma época específica, a palavra acaba por ser empregada nas mais diversas conotações, tanto que praticamente todas as ciências do homem a utilizam.

Neste sentido, as grandes transformações ocorridas no século passado geralmente vinculam-se ao termo "modernidade", embora as ciências humanas caracterizem a contemporaneidade como "pós-modernidade", e esta em si já se apresenta como uma fase de transição. Tal transição, conforme o autor ${ }^{32}$, consolida-se “à medida que se estratificam as novas formas de vida social desenvolvidas nesse período".

A pós-modernidade, para $\operatorname{Coelho}^{33}$, tem viés na superação do feudalismo e sua conversão na revolução industrial, porquanto seu principal efeito foi a possibilidade de transferência do trabalho humano para a máquina. No princípio, a máquina se limitava ao depender do homem para controlá-la. Ao entregar o controle da máquina à própria máquina,

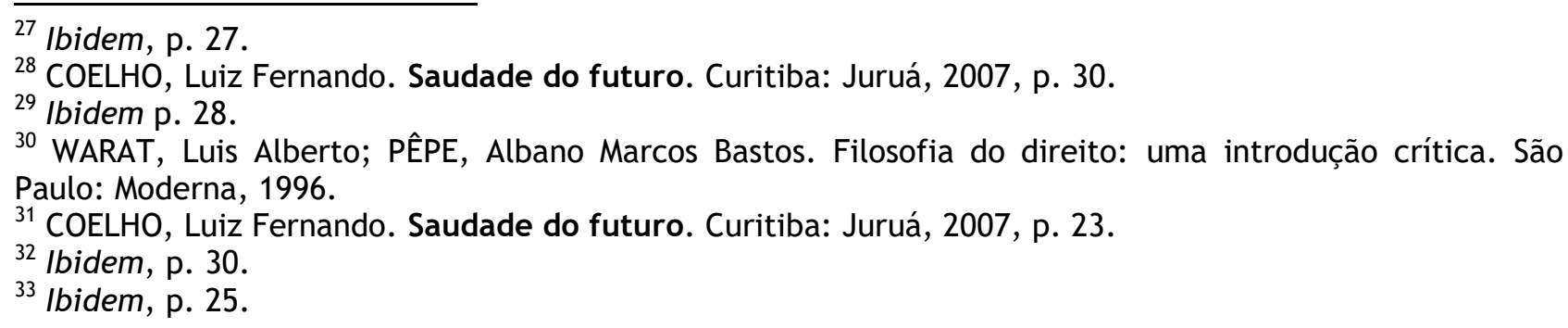


porém, faz-se um rompimento, que caracteriza a primeira aproximação à pós-modernidade, por ser uma possibilidade praticamente fantástica feita pelo aperfeiçoamento dos computadores.

$\mathrm{Na}$ mesma linha, o qualificativo “pós-moderno", segundo $\operatorname{Arnaud}^{34}$, ressaltou a importância atribuída ao espaço e à particularização dos espaços, especialmente no que diz respeito à pluralidade jurídica, fragmentação e transgressão.

Também neste sentido, aduz Coelho ${ }^{35}$ que a pós-modernidade está atrelada à difusão de diversos elementos, tais como novas formas de organização empresarial, urbana e familiar, articulando-se com a globalização e permeando espaços econômicos, políticos e jurídicos da sociedade. Desta forma, ela se expressa na busca de maior igualdade de oportunidades e de mercados, bem como maior anseio de democracia e justiça social ${ }^{36}$.

Deste modo, se o pensamento "moderno" pode ser definido por meio de certos critérios, também pode ser prudente a hipótese de que uma abordagem “pós-moderna” pode ser constituída pela superação daqueles primeiros critérios. Ou seja, se necessário encontrar critérios para um "pós-modernismo", um bom começo seria se referir, antes disso, ao “modernismo" 37.

Esse autor ${ }^{38}$ estabelece duas principais teses acerca da transformação da modernidade em pós-modernidade. A primeira delas é a análise da pós-modernidade no direito, que se caracteriza por uma preocupação de superação dialética do paradigma "moderno", fundado sobre inúmeros conceitos que englobam a abstração e axiomatização do próprio direito, do subjetivismo, da simplicidade e da segurança das relações jurídicas, separação da sociedade civil e do Estado, universalismo e unidade da razão jurídica.

A segunda tese de $\operatorname{Arnaud}^{39}$ é de que a crise contemporânea do Estado, do direito e da justiça, denunciada desde aproximadamente meio século, pode ter tido como causa o esgotamento das raízes das instituições, que, embora insuficientemente alimentadas pelo solo enfraquecido do pensamento ocidental “moderno", ainda procuram se expandir.

\footnotetext{
${ }^{34}$ ARNAUD, André-Jean. 0 direito entre modernidade e globalização: lições de filosofia do direito e do Estado. Tradução de Patrice Charles Wuillaume. Rio de Janeiro: Renovar, 1999, p. 200.

${ }^{35}$ COELHO, Luiz Fernando. Saudade do futuro. Curitiba: Juruá, 2007, p. 34.

${ }^{36}$ Ibidem, p. 34.

${ }^{37}$ ARNAUD, André-Jean. 0 direito entre modernidade e globalização: lições de filosofia do direito e do Estado. Tradução de Patrice Charles Wuillaume. Rio de Janeiro: Renovar, 1999, p. 201.

${ }^{38}$ Ibidem, p. 201.

${ }^{39}$ Ibidem Renovar, p. 202.
} 
Um direito pós-moderno, conforme entendimento de Arnaud ${ }^{40}$, caracteriza-se por uma vontade de pragmatismo e de relativismo, que se dá por meio do “descentramento do sujeito, por uma pluralidade das racionalidades, pelo risco que the é inerente, pelo retorno da sociedade civil e pela compreensão das relações jurídicas na complexidade das lógicas bruscamente estilhaçadas". Portanto, o pós-modernismo, para o autor, se caracteriza em si mesmo pela sua multiplicidade e pelo seu caráter plural ${ }^{41}$.

\section{O DESENVOLVIMENTO ECONÔMICO NA PÓS-MODERNIDADE}

Antes mesmo de se iniciar o debate acerca do Desenvolvimento Econômico, faz-se necessário adentrar na dimensão econômica da globalização, por sua direta relação com a chamada "economia-mundo".

A globalização, enquanto fenômeno, não tem fácil delimitação concreta de espaço, tempo, local, ou público específico, porque ela é um processo em marcha, extremamente dinâmico e envolvente. Neste sentido, atenta Santos ${ }^{42}$ que corriqueiramente há certa tendência em resumir as características dominantes do fenômeno à dimensão econômica.

O impacto da conversão da ciência e da tecnologia em fator básico de produção, de competitividade e de inovação contínua sobre a ordem econômica mundial, como explica Faria $^{43}$, passou a ser visto como marco de impulsão do fenômeno da globalização. Este, segundo o autor, constitui importante consequência da ênfase no conhecimento especializado como resposta à estagnação, à inflação e à deterioração das condições de lucratividade dos capitais financeiros trazidas pela crise do padrão monetário internacional.

Ainda que, desde o século XVI, seja admitida a existência de uma economia-mundo, não há dúvidas da grande intensificação pela qual passaram os processos de globalização nas últimas décadas. Este reconhecimento parte até mesmo daqueles que pensam que a economia internacional não é ainda uma economia global, em virtude da continuada importância dos mecanismos nacionais de gestão macroeconômica e da formação de blocos comerciais ${ }^{44}$.

\footnotetext{
${ }^{40}$ Ibidem, p. 202.

${ }^{41}$ ARNAUD, André-Jean. 0 direito entre modernidade e globalização: lições de filosofia do direito e do Estado. Tradução de Patrice Charles Wuillaume. Rio de Janeiro: Renovar, 1999, p. 234.

${ }^{42}$ SANTOS, Boaventura de Sousa. Pela mão de Alice: o social e o político na pós-modernidade. 7 ed. São Paulo: Cortez, 2000, p. 26.

${ }^{43}$ FARIA, José Eduardo. 0 direito na economia globalizada. São Paulo: Malheiros, 1999, p. 86.

${ }^{44}$ SANTOS, Boaventura de Sousa. Pela mão de Alice: o social e o político na pós-modernidade. 7 ed. São Paulo: Cortez, 2000, p. 289.
} 
De acordo com Faria45, as características da denominada "economia-mundo" são comuns aos de um “organismo", porque suas estruturas, limites e regras são variáveis, podendo permanecer iguais durante um longo período, alterando-se posteriormente, assim como podem estar fortes em dados momentos e fracos em outros.

Esta nova economia mundial, para $\operatorname{Santos}^{46}$, se caracteriza, especialmente, por grandes traços, como o investimento em escala global que domina o sistema financeiro; a flexibilização dos processos de produção multilocais; os baixos custos de transporte; a revolução nas tecnologias de informação e de comunicação; a desregulação das economias nacionais; a preeminência das agências financeiras multilaterais; e, por fim, a emergência de subgrupos de capitalismos transnacionais.

Não há dúvidas de que os processos de globalização, não somente o fenômeno em si, como também a sua dimensão econômica, produziram e continuam a produzir inúmeras transformações sociais em nível internacional, e consequentemente, na forma como se dá o desenvolvimento econômico.

Outro destaque frente a esta nova "economia-mundo", para Faria ${ }^{47}$, trata-se das profundas desigualdades e distorções nas trocas comerciais e fluxos de pagamentos, tecnológicos e de informações, especialmente nas relações entre as economias nacionais e os blocos regionais nas interações entre países “centrais", "semiperiféricos” e "periféricos”. Deste modo, a "economia-mundo" está longe de ser caracterizada como um consenso, ao contrário, em todas as suas dimensões, a "economia-mundo" acaba sendo definida por grandes contradições, conflitos permanentes e por tensões contínuas.

Neste sentido, a economia mundial se caracteriza pela existência de um grande número de Estados que aparentam uma estabilização no seu estágio ou nível de desenvolvimento. Estes Estados podem ser enquadrados, em linhas gerais, em duas grandes teorias: a da Modernização e da Dependência. Portanto, podem estar em uma posição intermediária entre a "maturidade" e o "atraso", como diriam os teóricos da modernização, ou então, segundo os teóricos da dependência, entre o "centro" e a "periferia"48.

\footnotetext{
${ }^{45}$ FARIA, José Eduardo. O direito na economia globalizada. São Paulo: Malheiros, 1999, p. 90.

${ }^{46}$ SANTOS, Boaventura de Sousa. A globalização e as ciências sociais. 2 ed. São Paulo: Editora Cortez, 2002, p. 29.

${ }^{47}$ FARIA, José Eduardo. O direito na economia globalizada. São Paulo: Malheiros, 1999, p. 94.

${ }^{48}$ ARRIGHI, Giovanni. A ilusão do desenvolvimento. Tradução de Sandra Guardini Teixeira Vasconcelos. Petrópolis, RJ: Vozes, 1997, p. 137.
} 
Como consequência, Santos $^{49}$ afirma que não se pode estranhar o fato de que o cisma global entre ricos e pobres tenha se aprofundado, quando, na época, calculava-se que 1 bilhão de pessoas vivia em pobreza absoluta, dispondo de um rendimento inferior a cerca de 365 dólares por ano. Esse abismo das condições de vida que se forma entre parcelas muito grandes da população do globo constitui um paradoxo preocupante. De um lado, há um inequívoco crescimento econômico, com maior volume de transações comerciais e financeiras, integração de mercados, e uma crescente incorporação das ciências como técnicas de produção, ampliando o acesso a bens e serviços e reduzindo os custos. De outro lado, porém, esses grandes ganhos da produtividade econômica e do acesso à tecnologia não tem revertido para a imensa parcela da população global.

Esse paradoxo, por sua vez, traz à tona necessariamente o tema do "desenvolvimento", porquanto, embora se considere a sociedade contemporânea, a economia e as técnicas “desenvolvidas", tal definição pouco diz sobre a realidade social e econômica de parcela muito expressa da humanidade. A conceituação do termo “desenvolvimento" não é simples, admitindo inúmeras teorias contrapostas. $\mathrm{Na}$ análise de $\mathrm{Sen}^{50}$, o desenvolvimento pode ser entendido como um processo de expansão das liberdades reais das pessoas, conceito este que contrasta às visões mais restritas de desenvolvimento, como as que denominam desenvolvimento o simples crescimento do Produto Nacional Bruto (PNB), aumento de rendas pessoais, industrialização, avanço tecnológico ou modernização social.

Para o autor ${ }^{51}$, o desenvolvimento exige, além do aumento de números econômicos absolutos, que se removam as principais fontes de privação de liberdade, como a pobreza, tirania, carência de oportunidades econômicas e destituição social sistemática, negligência dos serviços públicos e intolerância ou interferência excessiva de Estados repressivos na economia mundial. Na sua leitura, e de plano, evidencia-se que o conceito de desenvolvimento apresenta uma relação direta com o conceito de liberdade.

Por sua vez, na teoria de Arrighi ${ }^{52}$, ao se definir dois extremos no desenvolvimento, a "maturidade" e o "atraso", abre-se espaço para a existência de um grupo intermediário de Estados, em situação de instabilidade. Apesar de partirem de premissas diferentes, uma vez

\footnotetext{
${ }^{49}$ SANTOS, Boaventura de Sousa. A globalização e as ciências sociais. 2 ed. São Paulo: Editora Cortez, 2002, p. 293.

50 SEN, Amartya Kumar. Desenvolvimento como liberdade. Tradução de Laura Teixeira Motta; revisão técnica Ricardo Doniselli Mendes. São Paulo: Companhia das Letras, 2000, p. 17.

${ }^{51}$ Ibidem, p. 18.

52 ARRIGHI, Giovanni. A ilusão do desenvolvimento. Tradução de Sandra Guardini Teixeira Vasconcelos. Petrópolis, RJ: Vozes, 1997, p. 138.
} 
que, conforme a teoria da modernização, as posições intermediárias são temporárias porque são transicionais, os Estados passam a ocupar posições intermediárias no caminho virtual projetado do atraso à modernidade. De outro lado, de acordo com a teoria da dependência, as posições intermediárias são temporárias porque são residuais, o que quer dizer que as tendências polarizadoras da economia mundial acabarão por empurrar os Estados que ocupam posições intermediárias em direção ao centro ou em direção à periferia.

Cabe, porém, expor a crítica feita por $\operatorname{Arrighi}^{53}$ em sua obra, ao afirmar que ambas teorias, embora baseadas na perspectiva de sistemas mundiais, focalizam os Estados de forma individual, à medida que eles passam a ocupar posições intermediárias ou a experimentar “desenvolvimento dependente”. Isso, de certa forma, amplia a análise a diversos tipos de "falácias de composição", porque o que se julga verdadeiro, no caso de Estados individualmente, pode não ser verdadeiro para grupos de Estados. Assim, o autor questiona a errônea equivalência entre “desenvolvimento" e “industrialização", porque, ainda que as escolas discordem acerca dos fatores que fizeram alguns países se industrializaram e outros não, continuam a concordar quanto à equiparação de ambos os termos ${ }^{54}$.

Entendimento amplamente diferenciado, por sua vez, apresenta $\operatorname{Sen}^{55}$, que, acerca do crescimento econômico e da industrialização, afirma que a liberdade de entrar em mercados pode ser vista como uma importante contribuição para o desenvolvimento. Isso independente do que o mecanismo de mercado possa fazer ou não para promover o crescimento econômico ou a industrialização.

$\operatorname{Sen}^{56}$, nessa trilha, defende que o “êxito” de um Estado não deve ser analisado única e simplesmente pelo seu perfil econômico, mas sim por fatores sociais e econômicos conjuntamente, o que significaria analisar o êxito de uma sociedade com base primordial nas liberdades substantivas de que seus membros desfrutam. Ele justifica ainda que a avaliação e a eficácia são as duas razões que explicam a importância da liberdade individual no conceito de desenvolvimento, porque, na abordagem utilizada, as liberdades individuais substantivas são consideradas essenciais.

\footnotetext{
53 ARRIGHI, Giovanni. A ilusão do desenvolvimento. Tradução de Sandra Guardini Teixeira Vasconcelos. Petrópolis, RJ: Vozes, 1997, p. 139.

54 Ibidem, p. 208.

55 SEN, Amartya Kumar. Desenvolvimento como liberdade. Tradução de Laura Teixeira Motta; revisão técnica Ricardo Doniselli Mendes. São Paulo: Companhia das Letras, 2000, p. 21.

${ }^{56}$ Ibidem p. 32.
} 
0 autor $^{57}$ atenta ao fato de um grande número de pessoas terem sistematicamente negados os seus direitos civis básicos e sua liberdade política, propalando-se paradoxalmente, com frequência, que a negação desses direitos ajudaria a estimular o crescimento econômico. Nessa visão restrita, a restrição de liberdades poderia ser um hipotético fator benéfico ao acelerado desenvolvimento econômico, havendo quem defenda, inclusive, sistemas políticos mais autoritários, com negação de direitos civis e políticos básicos. Essa tese, denominada "tese de Lee", em referência ao ex-primeiro-ministro de Cingapura, Lee Yuan Yew, muitas vezes é defendida por meio de algumas evidências empíricas rudimentares. Porém, conforme elucida o autor, em comparações mais abrangentes entre países, não houve nenhuma confirmação desta tese, havendo poucos indícios de que a política autoritária, com restrição de liberdades, realmente auxilie o crescimento econômico.

No concernente à relação entre liberdade, desenvolvimento e industrialização, Arrighii ${ }^{58}$ faz referência à recente onda de desindustrialização entre os Estados mais ricos da economia capitalista mundial e a rápida industrialização dos Estados comparativamente pobres, que foi, em geral, considerada como equivalente a "desenvolvimento". Contudo, não foi questionada pelos estudiosos a possível combinação entre os processos conjuntos de industrialização/desindustrialização e um estreitamento da distância entre riqueza, poder e bem-estar.

De um lado, encontra-se o grupo de Estados ricos, mas em processo de desindustrialização e, do outro, o grupo de Estados não tão ricos, mas em processo de industrialização. Neste sentido, concordariam os defensores da dependência e da modernização que a industrialização é geralmente buscada não como objetivo, mas sim como meio na busca de riqueza, poder e bem-estar, ou, ainda, de uma combinação de todos estes. Deste modo, é necessário abandonar a ideia de que industrialização é o equivalente de desenvolvimento ${ }^{59}$.

Também se faz necessário dissociar a ideia de industrialização e desenvolvimento, mas conectar a discussão à forma como os indivíduos são diretamente impactados na vida em sociedade. Essa conexão, para Galtung ${ }^{60}$, ocorre entre o desenvolvimento e a satisfação progressiva das necessidades humanas, porque os direitos humanos se apresentam como um

\footnotetext{
${ }^{57}$ Ibidem, p. 29.

${ }^{58}$ SEN, Amartya Kumar. Desenvolvimento como liberdade. Tradução de Laura Teixeira Motta; revisão técnica Ricardo Doniselli Mendes. São Paulo: Companhia das Letras, 2000, p. 29.

${ }_{59}$ ARRIGHI, Giovanni. A ilusão do desenvolvimento. Tradução de Sandra Guardini Teixeira Vasconcelos. Petrópolis, RJ: Vozes, 1997, p. 208.

${ }^{60}$ GALTUNG, Johan. Direitos Humanos: uma nova perspectiva. Tradução de Margarida Fernandes. Lisboa: Instituto Piaget, 1994, p. 125.
} 
instrumento para o desenvolvimento. Essa ideia está intimamente ligada à teoria de Sen, de observar o êxito de uma sociedade pelas liberdades dos sujeitos. Ainda, tendo o desenvolvimento econômico como causa de aumento de poder, atenta Bobbio ${ }^{61}$ que, quanto mais aumentam os poderes dos indivíduos, tanto mais diminuem as liberdades desses mesmos indivíduos.

Neste sentido, percebe-se que a Declaração Universal trouxe uma ilusória certeza histórica de que toda a humanidade partilha de alguns valores comuns, criando a crença na universalidade de postulados, no sentido de que universal significa algo subjetivamente acolhido pela coletividade dos homens ${ }^{62}$. Contudo, ao considerar os desafios do desenvolvimento, como explica Sarlet ${ }^{63}$, o perene problema da eficácia e da efetivação dos direitos fundamentais segue tornando-se cada vez mais agudo, especialmente em face do fosso entre ricos e pobres. Por isso, deve-se analisar o desenvolvimento essencialmente como processo social, que, mesmo quando olhado pelo seu caráter puramente econômico, pode-se sempre ver a trama de relações sociais subjacentes $^{64}$.

\section{CONCLUSÃO}

A modernidade sustentou-se em três princípios, o Estado, a Sociedade e a Economia Liberal. O primeiro deles, o Estado, apresentou uma nova formulação de organização e de exercício do poder político da sociedade, tendo em vista que o esgotamento do modelo medieval abriu a oportunidade de emergência de novas relações de poder. O segundo, a Sociedade, constituiu a reformulação das relações sociais, devido ao esgotamento do paradigma até então centrado em organizações de produção hierarquizadas e servis nos feudos. E, por fim, o pilar da Economia Liberal fez com que o capitalismo e a classe burguesa emergissem, porque a estrutura dos feudos em relações predominantemente de troca não acompanhava mais a complexidade crescente da vida social e econômica.

\footnotetext{
${ }^{61}$ BOBBIO, Norberto. A era dos direitos. Tradução de Carlos Nelson Coutinho. Rio de Janeiro: Campus, 1992, p. 21.

${ }^{62}$ BOBBIO, Norberto. A era dos direitos. Tradução de Carlos Nelson Coutinho. Rio de Janeiro: Campus, 1992, p. 28.

${ }^{63}$ SARLET, Ingo Wolfgang. A eficácia dos direitos fundamentais. Porto Alegre: Livraria do Advogado, 1998 , p. 21.

${ }^{64}$ CARDOSO, Fernando Henrique; FALETTO, Enzo. Dependência e desenvolvimento na América Latina. 7. ed. Rio de Janeiro: Zahar Editores, 1970, p. 16.
} 
A superação da modernidade e sua passagem à pós-modernidade ocorreu atrelando-se outros elementos, como as novas formas de organização empresarial, urbana e familiar, ao mesmo passo em que se articulava com a globalização e permeava espaços econômicos, políticos e jurídicos da sociedade. Desta forma, a pós-modernidade expressa-se na busca complexa e tensa de maior igualdade de oportunidades e de mercados, bem como maior anseio de democracia e justiça social.

Paralelamente a isso, a noção de direitos fundamentais se altera frente às mudanças históricas ocorridas, porque o que parecia fundamental em uma época pode já não ser em outra, mas, por sua natureza, sempre serão Direitos Humanos. O elenco dos direitos do homem, portanto, passou por inúmeras modificações, especialmente em razão dos interesses das classes no poder, dos meios disponíveis para a realização desses interesses e das transformações técnicas, além de outros fatores que alteraram as condições históricas e modificaram a forma como a economia mundial se desenvolve.

Desta forma, a modernidade, quando relacionada diretamente com o desenvolvimento econômico, impacta o cenário dos direitos fundamentais, uma vez que, conforme Bobbio, os direitos declarados absolutos no final do século XVIII foram posteriormente submetidos a radicais limitações nas declarações contemporâneas.

Assim, os Direitos Fundamentais ultrapassaram a fase do debate inicial sobre sua conceituação, porque, na pós-modernidade, a questão principal consiste em analisar sua aplicação, migrando de uma discussão filosófica para uma discussão política.

$\mathrm{Na}$ mesma linha, o fenômeno da globalização econômica, enquanto processo em marcha, altera as dinâmicas locais, regionais e nacionais, impactando diretamente a sociedade contemporânea. Nesse contexto, o debate sobre o desenvolvimento apresenta grande relevância, e há, essencialmente, duas hipóteses a serem analisadas: a primeira, defendida por Arrighi, de que países que se encontram em posições intermediárias dificilmente irão se desenvolver suficientemente para saírem desta posição; e a segunda, defendida por Sen, de que o desenvolvimento de um país pode ser mensurado pelas liberdades de que seus cidadãos desfrutam, entendendo-se essas liberdades individuais como aquelas intrínsecas à pessoa humana, que podem ser incrementadas pelos programas governamentais de saúde, de educação, de saneamento básico e de habitação, entre outros que servem às necessidades dos cidadãos. Mesmo que sejam duas teses distintas, uma não necessariamente anula a outra, porque a diferença está nos parâmetros buscados, uma vez que, para Arrighi, há uma medida única de desenvolvimento, enquanto, para Sen, cada Estado deve ser analisado dentro de sua realidade. 


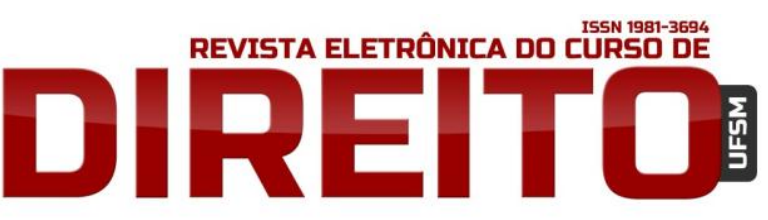

OS LIMITES DO DISCURSO DO DESENVOLVIMENTO ECONÔMICO E OS DIREITOS FUNDAMENTAIS: O CASO DA LIBERDADE NA PÓSMODERNIDADE

Frente a isso, conclui-se que aumentar o poder de países, classes e organizações faz com que estes mesmos sujeitos sejam afetados pela redução de suas liberdades individuais, alterando as dinâmicas não somente da economia mundial, mas também das políticas de desenvolvimento e especificamente do papel do Estado na Economia. Neste caso, a liberdade não é observada por Sen como o fim do desenvolvimento econômico, e sim, ao contrário, como o meio para atingi-lo.

Por isso, e em síntese, as questões encontram-se relacionadas: a modernidade altera as dinâmicas de Estado, Sociedade e Economia, e estas, juntamente com a globalização econômica, trazem à tona a problemática do desenvolvimento econômico, que impacta diretamente as liberdades humanas, assim entendidas como um Direito Fundamental. O grande desafio que se reserva, nesta quadra, é compatibilizar o discurso do desenvolvimento econômico com a efetividade dos direitos de liberdade.

\section{REFERÊNCIAS}

ALEXY, Robert. Teoría de los derechos fundamentales. 2. ed. Madrid. Centro de Estudios Politicos y Constitucionales, 2008.

ARNAUD, André-Jean. 0 direito entre modernidade e globalização: lições de filosofia do direito e do Estado. Tradução de Patrice Charles Wuillaume. Rio de Janeiro: Renovar, 1999.

ARRIGHI, Giovanni. A ilusão do desenvolvimento. Tradução de Sandra Guardini Teixeira Vasconcelos. Petrópolis, RJ: Vozes, 1997.

BOBBIO, Norberto. A era dos direitos. Tradução de Carlos Nelson Coutinho. Rio de Janeiro: Campus, 1992.

CARDOSO, Fernando Henrique; FALETTO, Enzo. Dependência e desenvolvimento na América Latina. 7. ed. Rio de Janeiro: Zahar Editores, 1970.

COELHO, Luiz Fernando. Saudade do futuro. Curitiba: Juruá, 2007.

FARIA, José Eduardo. O direito na economia globalizada. São Paulo: Malheiros, 1999.

GALTUNG, Johan. Direitos Humanos: uma nova perspectiva. Tradução de Margarida Fernandes. Lisboa: Instituto Piaget, 1994.

HOBBES, Thomas. Leviatã: ou matéria, forma e poder de um estado eclesiástico e civil. Tradução de Rosina D. Angina. 2 ed. São Paulo: Martin Claret, 2012. 


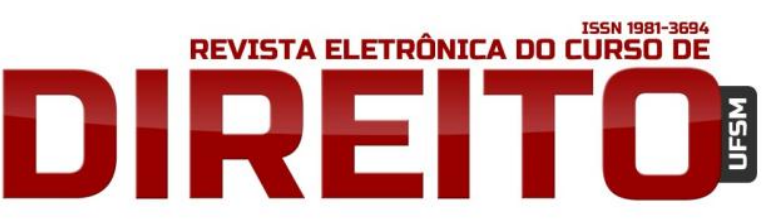

OS LIMITES DO DISCURSO DO DESENVOLVIMENTO ECONÔMICO E OS DIREITOS FUNDAMENTAIS: O CASO DA LIBERDADE NA PÓSMODERNIDADE

LOCKE, John. Segundo tratado sobre o governo civil: ensaio sobre a origem, os limites e os fins verdadeiros do governo civil. Tradução de Magda Lopes e Marisa Lobo da Costa. Petrópolis, RJ: Vozes, 1994.

ROUSSEAU, Jean-Jacques. Discurso sobre a economia política e do Contrato Social. Tradução de Maria Constança Peres Pissarra. Petrópolis: Vozes, 1996.

SANTOS, Boaventura de Sousa. Pela mão de Alice: o social e o político na pós-modernidade. 7 ed. São Paulo: Cortez, 2000.

. A globalização e as ciências sociais. 2.ed. São Paulo: Editora Cortez, 2002.

SARLET, Ingo Wolfgang. A eficácia dos direitos fundamentais. Porto Alegre: Livraria do Advogado, 1998.

SEN, Amartya Kumar. Desenvolvimento como liberdade. Tradução de Laura Teixeira Motta; revisão técnica Ricardo Doniselli Mendes. São Paulo: Companhia das Letras, 2000.

WARAT, Luis Alberto; PÊPE, Albano Marcos Bastos. Filosofia do direito: uma introdução crítica. São Paulo: Moderna, 1996. 